\title{
General practice consultations with obese children - a missed opportunity? Cross-sectional study using linked national child measurement and primary care data
}

Carol Dezateux, Nicola Foster, Zaheer Ahmed, Kate Homer, Alexander Miller, Marian Priebe, John Robson, Kambiz Boomla

\section{Background}

One third of children leaving primary school are obese. Child weight status information from the National Child Measurement Programme (NCMP) is not routinely shared with general practitioners (GPs). We hypothesised that obese children were more likely to consult their GP for obesity or weight-management than healthy-weight children.

\section{Methods}

NCMP data from 2013-2016 for City and Hackney were linked to coded GP data using pseudonymised NHS numbers, resulting in 13663 (93\%) linked records. NCMP-assigned weight status was based on the UK90 clinical reference, and obesity and weight-management consultations identified (Read codes: C38..; 66C..; 8HHH\%; 9N1yK; 22A\%). The odds of $\geq 1$ obesity or weightmanagement consultation in the school year of NCMP measurement among obese compared with healthy-weight children were estimated using logistic regression.

\section{Findings}

Obesity was identified in 624 (8.6\%) of 7275 five-year-olds (3721 (51.2\%) boys; median (IQR) age: 5.01 (4.76-5.27) years) and 1220 (19.1\%) of 6388 11-year-olds (3297 (51.6\%) boys; median (IQR) age: 10.87 (10.59-11.11 years). Obesity was more prevalent in boys than girls: $(9.5 \%$ (353/3721) and $7.6 \%$ (271/3554); 19.5\% (643/3297) and 18.7\% (577/3091) at ages five and 11 respectively. Obese children were more likely than healthy-weight children to consult for obesity or weightmanagement: respectively at age five: boys: $19.8 \%$ (70/353) vs $13.5 \%(391 / 2900)$; girls: $16.2 \%$ (44/271) vs $11.8 \%$ (342/2895); at age 11: boys: $17.0 \%$ (109/643) vs $12.6 \%$ (265/2111); girls: $19.9 \%$ $(115 / 577)$ vs $10.0 \%$ (200/1996). The odds $(95 \% \mathrm{Cl})$ of $\geq 1$ obesity or weight-management consultation in obese boys and girls respectively were $1.59(1.20,2.10)$ and $1.45(1.03,2.04)$ at age five, and $1.42(1.12,1.81)$ and $2.24(1.74,2.87)$ at age 11.

\section{Interpretation}

Although more likely to consult their GP for obesity or weight-management in the period before or after identification of obesity in the NCMP, fewer than one fifth of obese children attending primary schools in a London Borough with one of the highest child obesity rates in England do so. This is, to our knowledge, the first study linking NCMP to primary care data. Further work is needed to evaluate routine sharing of NCMP data with GPs and primary care-initiated weight-management support for children and their families.

\section{Declarations of Interests}

We declare no competing interests. 


\section{AUTHORS}

Carol Dezateux MD (Professor) ${ }^{1,2}$

Nicola Foster MSc ${ }^{1,2}$

Zaheer Ahmed $\mathrm{MSc}^{1}$

Kate Homer $\mathrm{MSc}^{1}$

Alexander Miller $\mathrm{MSc}^{3}$

Marian Priebe $\mathrm{MSc}^{1}$

John Robson $\mathrm{MD}^{1}$

Kambiz Boomla MSc ${ }^{1}$

${ }^{1}$ Clinical Effectiveness Group

Centre for Primary Care \& Public Health

Yvonne Carter Building

58 Turner Street

London $\mathrm{E} 12 \mathrm{AB}$

${ }^{2}$ Life Course Epidemiology and Biostatistics

UCL Great Ormond Street Institute of Child Health

30 Guilford Street

London WC1N 1EH

${ }^{3}$ City \& Hackney Public Health Team

3rd Floor, Hackney Service Centre

1 Hillman Street

London E8 1DY

Correspondence to:

Professor Carol Dezateux

Life Course Epidemiology and Biostatistics

UCL Great Ormond Street Institute of Child Health

30 Guilford Street

London WC1N 1EH

c.dezateux@qmul.ac.uk

Published abstract at https://doi.org/10.1016/S0140-6736(17)32972-0 